\title{
EVALUATION OF INDEX OF CARDIO-ELECTROPHYSIOLOGICAL BALANCE AND TP-E/QT RATIO IN COVID-19 PATIENTS TREATED WITH HYDROXYCHLOROQUINE AND AZITHROMYCIN
}

\author{
Songül Araç ${ }^{1}$, Mehmet Zülkif Karahan ${ }^{1}$, Mehmet Özel ${ }^{1}$, Ramazan Yiğit ${ }^{2}$, hasan akkoç ${ }^{3}$, \\ and Eşref Araç ${ }^{1}$ \\ ${ }^{1}$ Diyarbakir Gazi Yasargil Training and Research Hospital \\ ${ }^{2}$ Ergani State Hospital \\ ${ }^{3}$ Dicle University Medical Faculty
}

November 1, 2020

\begin{abstract}
Aim: The common cardiac toxicities of hydroxychloroquine (HCQ) and azithromycin(AZ) are not well defined in COVID -19 patients. The purpose of this study was to evaluate ventricular repolarization in COVID-19 patients treated with HCQ and AZ using iCEB, Tp-e interval, Tp-e/QT ratio, and Tp-e/QTc ratio. Methods: This retrospective study enrolled 164 patients diagnosed with COVID-19 pneumonia in the Emergency Department (ED) and then transferred to the medical floor or ICU in April 2020 Result: A total of 164 patients were mean aged $47 \pm 18$ years (range, 18-97 years) and $83(50.6 \%)$ were women in study population. Group HTQ had 38 patients, Group HTQ + AZ had 126 patients. On the 5th day of hospitalization heart rates $(\mathrm{HR})$ were significantly lower than $\mathrm{ED}(\mathrm{p}<0,001)$. On the 5th day of hospitalization QTc, QT max (V5-V6), QTmin, Tp-e (V5-V6) and iCEB values were significantly higher than ED ( $\mathrm{p}=0,01$ and all the rest $\mathrm{p}<0,001$ respectively). On the 5th day of hospitalization $\mathrm{iCEB}$ values of $\mathrm{HTZ}+\mathrm{AZ}$ group were statistically significant higher than iCEB values of HTQ group ( $\mathrm{p}=0,03$ ). iCEBc had strong correlation between Tp-e/QT (V5). iCEBc had strong negative correlation between Tp-e (V5). Conclusion: The iCEB values were significant increased after HTQ and AZ treatment in COVID-19 patients. We think that iCEB is a more sensitive marker than QT prolongation in predicting the risk of multi-drug arrhythmia.
\end{abstract}

\section{Hosted file}

Manuscript.pdf available at https://authorea.com/users/354116/articles/490180-evaluationof-index-of-cardio-electrophysiological-balance-and-tp-e-qt-ratio-in-covid-19-patientstreated-with-hydroxychloroquine-and-azithromycin 